\title{
Asilos diplomáticos na América Latina: debates e diferentes práticas ao longo da segunda metade do século XIX ${ }^{1}$.
}

\section{Diplomatic asylum in Latin America: debates and different practices on the second half of the 19th Century.}

\author{
João Júlio Gomes dos Santos Júnior²
}

\begin{abstract}
Resumo A prática de solicitar asilo em espaços beneficiados pela extraterritorialidade, tais como embaixadas, consulados e navios de guerra, era algo comum em todo mundo ao longo do século XIX. Porém, a América Latina se notabilizou nesse período pelo elevado número de casos em que indivíduos buscaram conscientemente utilizar as fronteiras extraterritoriais para escapar de perseguições políticas. Em uma época marcada pela ausência de organismos internacionais reguladores e onde a lei era consuetudinária, cada episódio se tornava uma negociação diplomática na qual a jurisprudência era usada para sustentar os posicionamentos governamentais. Este artigo procura explorar alguns casos ilustrativos na América Latina onde: 1) o asilo foi mantido; 2) os refugiados foram entregues após negociação; 3) o asilo foi transgredido. A principal hipótese levantada é de que o mecanismo jurídico de proteção dos asilados não apenas representou uma importante etapa para o desenvolvimento dos direitos humanos, como também pode ter colaborado para a instabilidade política da América Latina.
\end{abstract}

Palavras-Chave América Latina; asilos diplomáticos; extraterritorialidade.

\begin{abstract}
The practice of requesting asylum in spaces benefited from extraterritoriality, such as embassies, consulates and warships, was common around the world throughout the nineteenth century. But Latin America was notable in that period by the high number of cases in which individuals have sought to consciously use the extraterritorial borders to escape political persecution. In an era marked by the absence of international regulatory agencies and where the law was customary, each episode became a diplomatic negotiation in which jurisprudence was used to sustain government positions. This article seeks to explore some illustrative cases in Latin America where: 1) asylum was maintained; 2) the refugees were delivered after negotiation; 3) asylum was violated. The main hypothesis is that the legal mechanism of
\end{abstract}

\footnotetext{
${ }^{1}$ Doutor em História pela Pontifícia Universidade Católica do Rio Grande do Sul (PUCRS). Bolsista de Pósdoutorado CAPES/PNPD, na Universidade Federal de Pelotas (UFPel). Título da pesquisa em andamento: Asilos diplomáticos na América Latina no "longo século XIX” (1789-1914). E-mail: jjjhst@gmail.com.

${ }^{2}$ Este artigo é o resultado de comunicações realizadas em congressos nacionais e internacionais entre 2014 e 2015 , com destaque para o 24th Annual World History Association Conference, ocorrido em 2015 na cidade de Savannah, no Estado da Georgia - EUA (em que recebemos o apoio AEX/Junho da CAPES), assim como o Simpósio Temático “A História Global em debate: métodos, historiografia e estudos de casos”, ocorrido em 2015 dentro do XXVIII Simpósio Nacional de História da ANPUH, na cidade de Florianópolis - SC.
}

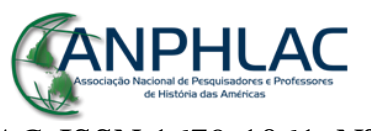

Revista Eletrônica da ANPHLAC, ISSN 1679-1061, №. 19, p. 06-24, jul./dez., 2015.

http://revista.anphlac.org.br 
protection of exiled people not only represented an important step for the development of human rights, as also may also have contributed to political instability in Latin America.

Key Words Latin America; diplomatic asylum; extraterritoriality

Artigo recebido em: 23/08/15

Artigo aprovado para publicação em: 06/11/2015

\begin{abstract}
É surpreendente testemunhar a prontidão e a convicção com que os revolucionários derrotados se aproximam da porta destes lugares exigindo, como uma questão de direito, admissão e proteção ${ }^{3}$. (MOORE, 1892, p. 222).
\end{abstract}

Comentário do Ministro dos Estados Unidos no Haiti, Mr. Langston, em relatório diplomático do ano de 1878.

De acordo com a reportagem publicada no dia 20 de abril de 2015 no site alemão Deutsche Welle, o Alto Comissariado das Nações Unidas para os Refugiados (Acnur) confirmou que apenas nos quatro primeiros meses desse ano já havia registros de mais de 1.500 vítimas da travessia marítima entre a África e a Europa ${ }^{4}$. O elevado número de pessoas que arriscam suas vidas em embarcações precárias em busca de refúgio do outro lado do Mediterrâneo trazem à tona a necessária discussão sobre as políticas de asilo, refúgio e direitos humanos, não apenas na Europa, mas em todo o mundo.

O debate sobre a internacionalização dos direitos humanos e os mecanismos de proteção dos refugiados são preocupações constantes, tanto no âmbito jurídico quanto acadêmico. De acordo com José B. Acosta Estévez (2005), a atual proteção dos refugiados se dá simultaneamente no âmbito do direito internacional dos refugiados assim como no campo do direito internacional dos direitos humanos. Ou seja, hoje existem regramentos internacionais que visam garantir determinados direitos básicos dos seres humanos quando os mesmos são colocados em situações limites.

No passado, entretanto, nem sempre foi assim. Como bem demonstrou Lynn Hunt (2009), a ideia de direitos humanos é uma invenção de fins do século XVIII e meados do século XIX. Um longo caminho teve que ser percorrido até que houvesse uma Declaração Universal dos Direitos Humanos, o que ocorreu apenas em 1948 em um contexto de pós-Segunda Guerra

\footnotetext{
3 Tradução livre do inglês: "It is surprising to witness the readiness and assurance with which a defeated revolutionist approaches the door of such places, demanding, as matter of right, admission and protection".

4 "Tragédias no Mediterrâneo mudam rotina de Lampedusa". Matéria de autoria de Angelo van Schaik e Theresa Krinninger. Disponível em: http://www.dw.com/pt/tragédias-no-mediterrâneo-mudam-rotina-de-lampedusa/a18388573 Acesso em: 22 de agosto de 2015.
}

\title{
BANPHLAC
}

Revista Eletrônica da ANPHLAC, ISSN 1679-1061, №. 19, p. 06-24, jul./dez., 2015.

http://revista.anphlac.org.br 
Mundial em que o mundo assistira estarrecido os horrores das migrações forçadas e as políticas de eliminação de minorias étnicas.

Para compreender as mudanças advindas com essas efemérides do século XX (Primeira e Segunda Guerra Mundial), é preciso refletir sobre a construção desses direitos internacionais ao longo do século XIX. Essa trajetória foi marcada por momentos de negociação e conflito em uma época que não havia instituições reguladoras das práticas internacionais. $\mathrm{O}$ direito internacional ainda se baseava no direito consuetudinário, assim como os manuais de época funcionavam como uma coleção de jurisprudências para orientar a prática diplomática.

Como veremos ao longo desse artigo, é nesse cenário que se desenvolveram as práticas de proteção jurídica dos asilos diplomáticos. Para compreender esse fenômeno histórico, assim como suas diferenças em relação a outros, tais como refúgios e exílios, vamos dividir esse texto em quatro partes. A primeira parte busca uma contextualização das recorrentes formas com que os homens buscaram proteção ao longo da história. Na segunda parte, serão discutidas algumas obras que pensaram o direito internacional ao longo do século XIX. Essas obras funcionavam como manuais cheios de exemplos históricos que eram usados como jurisprudência para auxiliar na resolução de casos semelhantes. Além disso, os autores possuíam entendimentos diversos, e por vezes divergentes, sobre os asilos diplomáticos, o que contribuiu para confusões terminológicas presentes até os dias de hoje.

A terceira parte procura levantar alguns episódios ocorridos na América Latina, onde: 1) o asilo foi mantido; 2) os refugiados foram entregues após negociação; 3) o asilo foi transgredido. Longe de querer estabelecer uma tipologia fixa sobre os asilos diplomáticos, nossa intenção é apenas ilustrar algumas das soluções possíveis e demonstrar a complexidade desse fenômeno histórico. Por fim, a quarte parte será uma breve consideração final sobre o fenômeno dos asilos diplomáticos na América Latina no transcorrer do século XIX.

\section{A recorrente busca por proteção.}

A prática de buscar proteção para escapar de perseguições é algo comum e recorrente na história e possui uma tradição que remonta à antiguidade clássica. Entre os gregos, por exemplo, alguns templos possuíam um caráter sagrado que impedia momentaneamente que o refugiado fosse capturado no seu interior. Se o indivíduo fosse inocente ninguém poderia

\section{GANPHLAC}

Revista Eletrônica da ANPHLAC, ISSN 1679-1061, №. 19, p. 06-24, jul./dez., 2015.

http://revista.anphlac.org.br 
retirá-lo de dentro do templo. Porém, se fosse considerado culpado, o fato de ter se refugiado dentro de um templo não o isentava do castigo (ZARATE, 1958, p. 22).

Entre os romanos, a concessão de proteção individual a perseguidos era extremamente rígida por ser inconciliável com os princípios jurídicos do dura lex sed lex ("a lei é dura mas é a lei”). Entre as poucas possibilidades existentes para escapar da condenação estava o encontro fortuito com uma sacerdotisa vestal quando um condenado fosse conduzido ao suplício. O indivíduo era poupado se ela jurasse que o encontro havia sido casual. Outra possibilidade era buscar refúgio na casa de um Flamen Dialis, um sacerdote de Júpiter. No momento em que o perseguido pisava dentro desse espaço passava a ser considerado livre. Foi mais tarde, depois que o imperador Constantino defendeu a religião católica como credo oficial entre os romanos, que as igrejas passaram a ser os espaços de proteção aos indivíduos perseguidos, caracterizando, assim, a noção de asilo religioso (Idem, 1958, p. 24).

As igrejas continuaram a conceder proteção aos criminosos ao longo de toda a época medieval. Contudo, nesse mesmo período surgiu outro tipo de amparo aos perseguidos que se baseava nas disputas e rivalidades existentes entre os senhores feudais. O asilo feudal beneficiava os indivíduos que exploravam as diferenças de domínio ao buscar refúgio em outro feudo (GIGENA, 1960, p. 22).

O surgimento dos primeiros Estados nacionais, estruturados a partir da delimitação territorial, centralização burocrática e monopólio do uso da força (ELIAS, 1990), marcou uma importante transição na tradição de conceder proteção a refugiados. Os indivíduos passaram a usar a perenidade entre as fronteiras nacionais para se deslocar de uma soberania à outra e escapar das perseguições policiais, que não podiam perseguir os indivíduos depois que os mesmos saíam de seu alcance jurisdicional. Dessa prática, surgiu o chamado asilo territorial (VIADEMONTE, 1961).

Junto com o surgimento dos Estados modernos tornou-se necessário o estabelecimento de missões diplomáticas permanentes para representação constante entre os países. Os embaixadores, assim, eram enviados para executar essa função. Esses diplomatas eram considerados invioláveis no exercício do seu cargo para garantir que não fossem coagidos a tomar decisões que contrariassem os interesses de seus respectivos países. Com o tempo, a inviolabilidade dos embaixadores foi estendida para sua residência, familiares e funcionários. A partir de então, o espaço da embaixada passou a ser considerado um lugar seguro onde

\section{GANPHLAC}

Revista Eletrônica da ANPHLAC, ISSN 1679-1061, №. 19, p. 06-24, jul./dez., 2015. http://revista.anphlac.org.br 
pessoas que fugiam de perseguições poderiam obter refúgio. Foi assim que, da inviolabilidade dos embaixadores, surgiu o asilo diplomático (ZARATE, 1958; MAGALHÃES, 2005).

Pode-se dizer que o asilo diplomático substituiu o asilo religioso com o surgimento dos Estados modernos. Porém, as duas instituições possuem uma diferença fundamental: se antes o asilo baseava-se na sacralidade dos templos e igrejas, agora passou a fundamentar-se na inviolabilidade dos diplomatas e embaixadas (ZARATE, 1958) ${ }^{5}$.

Diversos tratadistas reconheceram a inviolabilidade do asilo diplomático, tais como Conradinus Brunos (1558), Alberico Gentili (1585) e Francisco Suárez (1613). Entretanto, nenhum desses pensadores fundamentou essa prática, apenas as consideravam válidas por costume. Foi Hugo Grotius (1625) que sistematizou essa ideia com a criação da ficção da extraterritorialidade, que passou a considerar as embaixadas como uma porção territorial do país que representavam. Dessa forma, o asilo diplomático alcançou o mesmo patamar jurídico do asilo territorial, pois buscar refúgio dentro de uma embaixada seria o mesmo que cruzar a fronteira de um Estado (GIGENA, 1960).

Ao longo da história dos asilos há ainda um momento de inflexão fundamental. Durante muito tempo, os únicos indivíduos beneficiados por esse recurso jurídico foram aqueles perseguidos por crimes comuns. Quando os refugiados eram considerados criminosos políticos, o direito de asilo não era reconhecido. Essa diferença residia justamente no delito em questão: quando a contravenção era considerada comum não havia um grande interesse de vingança para além de alguns poucos prejudicados diretamente; porém, quando o crime era considerado político, colocava-se em questão a própria estabilidade de um governo (GIGENA, 1960).

Este foi o caso, por exemplo, do conflito que se estabeleceu entre a república de Veneza e o reino da França em 1540. Um grupo de altos funcionários da república veneziana teria facilitado o acesso a documentos governamentais sigilosos aos representantes do Império Otomano, o que possibilitou a assinatura de um tratado favorável aos otomanos e prejudicial aos interesses da república veneziana. Entre esses funcionários estava Constantino Cavazza, secretário do Conselho dos Dez; Nicolás Cavazza, membro do Consiglio dos Pregadi, o senado de então; e também outros indivíduos como Agustín Abondio, Juan Francisco Valerio e outros.

\footnotetext{
${ }^{5}$ Também houve casos de abusos relacionados à inviolabilidade dos diplomatas. Em alguns casos, os diplomatas reivindicavam o Franchise des quartiers ou jus quarteriorum, que estendia a jurisdição dos embaixadores para além de sua residência englobando bairros inteiros e isentando-os da soberania local. Na prática, esses espaços passaram a abrigar criminosos que pagavam aluguéis para se beneficiar da proteção extraterritorial. Esses abusos foram contidos a partir de negociações bilaterais baseadas na reciprocidade (GIGENA, 1960, p. 39).
}

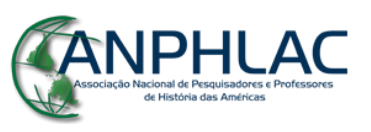

Revista Eletrônica da ANPHLAC, ISSN 1679-1061, №. 19, p. 06-24, jul./dez., 2015.

http://revista.anphlac.org.br 
Quando a traição foi descoberta, Cavazza, Abondio e Valerio buscaram asilo na embaixada da França e acordaram a proteção com o diplomata Guillermo Pellisier, o Duque de Montpellier. O Conselho dos Dez negou-se a reconhecer o direito de asilo por tratar-se de réus de alta traição política. Ao mesmo tempo, o embaixador francês recusava-se a entregá-los para serem julgados. Com o impasse estabelecido, o governo veneziano autorizou que dois canhões fossem instalados em frente à residência diplomática para forçar a entrega dos indivíduos. O Duque de Montpellier cedeu frente à ameaça e entregou os perseguidos que foram imediatamente enforcados na Praça de São Marcos.

O episódio causou a ira do soberano francês Francisco I, que se negou a receber o embaixador veneziano Antonio Venier. Porém, a república de Veneza argumentou que não se tratava de um desrespeito ao governo francês ou à autoridade do embaixador, mas sim um ato que visava apenas garantir o direito do governo de punir os perseguidos políticos. No final, o conflito não gerou maiores problemas. Contudo, quase setenta anos depois, o governo inglês invocaria esse mesmo episódio como jurisprudência contra a própria Veneza, quando um capelão escreveu um livro contra a rainha Elisabeth e procurou asilo junto ao embaixador veneziano em Londres, Marco Antonio Correr. O governo inglês utilizou o caso Cavazza, Abondio e Valerio como argumento para exigir a entrega do capelão às autoridades inglesas. $\mathrm{O}$ diplomata veneziano não teve outra opção a não ser concordar com a solicitação (ZARATE, 1958; GIGENA, 1960).

A historiografia é prolixa em exemplos semelhantes a este ao longo dos séculos XVII e XVIII. Entretanto, com o contexto iluminista, a Independência dos Estados Unidos e a Revolução Francesa de 1789, foi inaugurada uma nova fase na história dos asilos. Junto com a defesa das noções de Liberdade, Igualdade e Fraternidade, os franceses propagaram os Direitos do Homem e dos Cidadãos, que defendia, sobretudo, o direito dos indivíduos à vida (HUNT, 2009).

Com essas novidades, os franceses operaram uma grande mudança na compreensão do asilo ao defender que o benefício deveria ser concedido justamente aos criminosos políticos, pois esses indivíduos estariam com suas vidas em risco. A defesa se materializou no artigo $120^{\circ}$

\section{GANPHLAC}


da Constituição de 1793, que previa "a concessão de asilo aos estrangeiros desterrados de sua pátria pela causa da liberdade" (VIADEMONTE, 1961, p. 13)6.

A partir de então, a França passou a ser considerada "a terra da liberdade" e atraiu diversos grupos de emigrados de outros estados que eram perseguidos justamente por serem considerados "criminosos políticos" em seus países de origem (BURGESS, 2008). A partir de 1789, e ao longo de todo o século XIX, o asilo diplomático deixou de ser um benefício jurídico que abrangia os criminosos comuns passando a alcançar, justamente, os criminosos políticos.

Desde que houve o reconhecimento que os asilos diplomáticos deveriam beneficiar exatamente os criminosos políticos e não mais os criminosos comuns, estabeleceu-se um debate conceitual pela definição do delito. Afinal, quais os crimes ou atitudes que poderiam ser caracterizados como contravenções políticas e quais deveriam assumir o status de delinquências comuns? Esse ponto gerou diversas discussões e negociações. A solução adotada foi reconhecer que a responsabilidade pela definição do delito político (e consequentemente da validade sobre o direito de asilo) caberia ao Estado de asilo. Ao mesmo tempo, também se reconhecia ao Estado territorial o direito de impetrar um processo de extradição contra o asilado, que nada mais é que um acordo bilateral entre os países para devolução de criminosos para serem julgados pelos seus crimes no país de origem. Ou seja, se, por um lado, o asilo diplomático era garantido contra as perseguições políticas, por outro lado, a extradição impedia a impunidade do criminoso comum. De acordo com Viademonte (1960, p. 103), essas duas instituições se complementam e se correspondem.

\section{Pensando o asilo diplomático no século XIX.}

Ao longo do século XIX, o asilo diplomático gerou muitas dúvidas e discussões entre os pensadores do direito internacional, sobretudo em relação ao seu aspecto extraterritorial e também em relação ao público beneficiado por esse mecanismo jurídico. De uma maneira geral, essa época ficou marcada pela publicação de diversos manuais que buscavam recolher as

\footnotetext{
${ }^{6}$ Tradução livre do espanhol: "Se concede Derecho de Asilo a los extranjeros desterrados de su patria por la causa de la libertad".
}

\section{GANPHLAC}

Revista Eletrônica da ANPHLAC, ISSN 1679-1061, №. 19, p. 06-24, jul./dez., 2015.

http://revista.anphlac.org.br 
experiências vistas como clássicas assim como as últimas novidades em termos de jurisprudência para criar linhas gerais de procedimentos diplomáticos.

Há uma vasta pluralidade de autores e obras que foram publicadas durante esse período. Seria impossível dentro desse espaço dar conta de todos. Dessa forma, optamos por analisar três autores de diferentes nacionalidades para avaliar as semelhanças, diferenças e conexões existentes nos seus escritos em relação ao direito de asilo. Selecionamos o venezuelano Andrés Bello, o brasileiro Carlos Vidal de Oliveira Freitas e o estadunidense John Bassett Moore.

Andrés Bello foi um dos enviados pelo governo venezuelano para obter o reconhecimento da independência nacional junto à Inglaterra no ano de 1810. As circunstâncias fizeram com que ele permanecesse em Londres durante 19 anos, período em que teve a oportunidade de estudar e ter contato com a produção intelectual mais refinada da época. Em 1829, ele retornou para o continente americano, mas não para sua terra natal, e sim para o Chile, onde ele recebeu apoio governamental e assumiu cargos importantes que o possibilitaram desenvolver o seu pensamento jurídico (RACINE, 2000).

Alguns anos depois, em 1832, ele publicou em Valparaíso o livro Principios del Derecho de Gentes, que rapidamente alcançou o patamar de clássico, tendo sido reeditado várias vezes sob o título de Principios de derecho internacional. De acordo com Héctor Gros Espiell (1982, p. 23), “entre 1832 y 1865 se le conoció en todos nuestros países, fue texto universitario, libro de consulta para las Cancillerías y sirvió de inspiración y de modelo a la incipiente doctrina del Derecho Internacional, que comenzaba a surgir entre nosotros".

Em sua obra, Andrés Bello defende, por um lado, o direito de asilo aos delitos políticos ou em casos de crimes de lesa majestade, uma "regla que parece tener su fundamento en la naturaleza de los actos que se califican con este título, los cuales no son muchas veces delitos, sino a los ojos de los usurpadores y tiranos" (BELLO, 1886, p. 116). Por outro lado, o pensador venezuelano considera que os criminosos que tivessem infringido as leis da natureza e dos sentimentos de humanidade como os assassinos, por exemplo, não deveriam encontrar proteção.

O brasileiro Carlos Vidal de Oliveira Freitas era Primeiro Tenente da Armada Brasileira e Professor de Direito Internacional Marítimo na Escola Naval quando, em 1884, ele lançou o livro intitulado Elementos de Direito Internacional Marítimo. A obra buscava servir

\section{GANPHLAC}


de referência para os Guardas Marinhas do $4^{\circ}$ ano daquela escola. Logo nas primeiras páginas do livro há uma lista do "quadro geral dos autores compulsados". Ali é possível vislumbrar uma série de autores ingleses, franceses, italianos, alemães e latino-americanos (incluindo alguns brasileiros), mostrando a importante circulação de impressos na época.

A obra é interessante por salientar outro espaço de asilo diplomático para além das embaixadas, nomeadamente os navios de guerra, que se beneficiam do mesmo princípio de extraterritorialidade que também os torna invioláveis, mesmo em águas territoriais de outro país. De acordo com Carlos Vidal de Oliveira Freitas,

\begin{abstract}
Os criminosos politicos para os quaes em geral a sanha dos partidos rompe os diques da Justiça, são mais facilmente recebidos a bordo. As guerras civis, as revoluções pódem forçar a individuos nellas envolvidos á procurar um refugio á bordo; a pratica das nações autorisa então os commandantes á receber esses refugiados e, sem ser um dever absoluto, não deixa de ser um dever moral o asylo em taes condições (FREITAS, 1884, p. 207).
\end{abstract}

Como se percebe, a visão de Carlos Vidal de Oliveira Freitas em relação ao asilo diplomático aproxima-se do mesmo entendimento de Andrés Bello. Para ambos, é aceitável a concessão de asilo para criminosos políticos que estiverem em revolta contra o seu governo. Essa não é a mesma opinião do diplomata estadunidense John Basset Moore, por exemplo. Esse autor publicou três artigos nos meses de março, junho e setembro de 1892, na revista Political Science Quarterly. A série de artigos intitulada Asylum in Legations and Consulates and in Vessels I, II, III (respectivamente) buscou detalhar e justificar a decisão dos Estados Unidos em recusar a concessão daquele benefício jurídico internacional ${ }^{7}$.

Para Moore, quem não deveria ser visto como criminoso político pelos Estados Unidos eram, em especial, as pessoas que mataram ou tentaram matar os membros-chaves do Estado ou suas famílias. Essas pessoas não deveriam ser tratadas como criminosos políticos em hipótese alguma. Além disso, Moore condenava enfaticamente a concessão de asilo para revolucionários:

Como tem sido mostrado, a concessão de asilo para criminosos políticos foi uma simples transformação de um abuso decadente, que saltou algumas vezes quando o princípio de soberania territorial não estava totalmente consagrado e quando os

\footnotetext{
${ }^{7}$ Pelo menos em discurso, uma vez que em nossa pesquisa rastreamos mais de 50 episódios de asilos em embaixadas, consulados e navios de guerra, dentre os quais os próprios Estados Unidos são o país que mais concedeu asilos diplomáticos na América Latina ao longo do século XIX, totalizando 21 episódios já mapeados.
}

\title{
CANPHLAC
}


privilégios dos embaixadores eram extremamente exagerados. É por causa dessa falha em considerar o asilo em seus aspectos legais como uma derrogação da soberania do Estado, que escritores têm, por vezes, suposto que uma exceção pode ser feita em favor a uma classe de criminosos em desfavor de outra. E suas consequências, destas tentativas em realizar tal exceção, que nós temos constantemente testemunhado no curso de nossas investigações, a intervenção diplomática, e até mesmo dos agentes consulares, nos negócios dos países em que eles residem fazendo de suas casas a base de operações daqueles envolvidos nas rixas políticas (MOORE, 1892, p. 405) ${ }^{8}$.

Como se vê, o autor estadunidense se posicionava contra a concessão de asilos aos criminosos políticos por entender que essa prática colaborava para a instabilidade política dos países ${ }^{9}$. Entretanto, essa não era uma opinião unânime entre os pensadores do século XIX.

De certa maneira, cada caso de asilo, ou refúgio (sinônimos no século XIX), configurava uma disputa pelo direito de definir o delito, se político ou não. A estrutura dessa disputa se manifestava em uma relação triangular composta entre o país que perseguia, o país que asilava e os próprios asilados (RONIGER; SZNAJDER, 2009) ${ }^{10}$. Cada polo dessa relação manifestava seu entendimento sobre o episódio em questão e buscava referendar seus argumentos em manuais do direito internacional da época e também por meio de jurisprudências.

\section{A notabilidade da América Latina e a jurisprudência.}

\footnotetext{
${ }^{8}$ Tradução livre do ingles: "As has been shown, the granting of asylum to political offenders was simply the transformation of a decaying abuse, which sprang up in times when the principle of territorial sovereignty was not fully established and when the privileges of ambassadors were greatly exaggerated. It is because of the failure to consider asylum in its true legal aspect as a derogation from the sovereignty of the state, that writers have sometimes seemed to suppose that an exception might be made in favor of one class of offenders as against another; and it is in consequence of the attempt to make such an exception that we have constantly witnessed, on the course of our investigations, the intervention of diplomatic and even consular officers in the affairs of the country in which they reside, by making their houses a base of operations for those engaged in political strife".

${ }^{9}$ Apenas para ilustrar outro autor latino-americano que também se colocava contra a concessão de asilo para criminosos políticos, vale citar o também venezuelano Rafael Seijas, na obra El Derecho Internacional HispanoAmericano (público e privado). Para ele, "Si se trata de un individuo acusado de un crimen de Estado y se averigua que se ha refugiado en el palacio del Ministro de una potencia extranjera, no sólo puede el Gobierno, cercando el palacio, impedir la evasión del culpado, sino también sacarle inmediatamente y aun por la fuerza, caso que el Ministro, aunque debidamente requerido por la autoridad competente, se negase á su extradición" (SEIJAS, 1884, p. 555).

${ }^{10}$ Essa estrutura triangular para analisar asilos diplomáticos é inspirada em Mario Sznajder e Luis Roniger (2009) em seu estudo sobre as políticas de exílio na América Latina. Esses autores defendem que no transcorrer do século XIX se estabeleceram relações políticas triangulares compostas pelo Estado que expeliu, os próprios exilados e o Estado que os hospedou. Para o século XX, Sznajder e Roniger defendem a necessidade de incorporar um quarto elemento de análise, nomeadamente uma arena global preocupada com os direitos humanos e leis humanitárias internacionais.
}

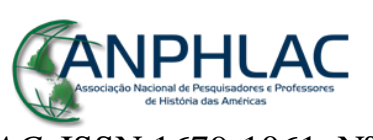

Revista Eletrônica da ANPHLAC, ISSN 1679-1061, №. 19, p. 06-24, jul./dez., 2015.

http://revista.anphlac.org.br 
Ao longo do século XIX, a América Latina se notabilizou pela quantidade de casos em que indivíduos buscaram, de forma consciente, utilizar as fronteiras extraterritoriais para escapar de perseguições políticas. Os episódios aconteceram em praticamente todos os países latino-americanos, sendo que na grande maioria dos casos foram as grandes potências européias e os Estados Unidos que concederam o benefício. Em nossa pesquisa atual mapeamos mais de 50 casos de asilos diplomáticos concedidos em embaixadas, navios de guerra, consulados e outros espaços.

Nossa intenção não é criar uma tipologia sobre as resoluções dos casos de asilos diplomáticos na América Latina. Nosso objetivo é mais modesto. Ao longo da pesquisa, verificamos que os episódios tiveram desdobramentos que variaram entre a aceitação e o respeito ao asilo; o estabelecimento de negociações para que os asilados fossem entregues ao país que os perseguia; e casos em que houve conflitos com a invasão dos espaços de asilo para retirada forçada dos asilados. Dessa forma, nosso objetivo aqui é apenas ilustrar alguns casos de asilo diplomático que tiveram distintas resoluções.

De uma maneira geral, a solução mais recorrente para esses episódios foi a aceitação do asilo e o acordo entre as partes para que o(s) indivíduo(s) fosse(m) escoltado(s) para fora do país. Este foi o caso, por exemplo, do asilo ao ex-governador de Buenos Aires, o general Juan Manuel de Rosas.

Em 1852, as tropas rosistas foram derrotadas na batalha de Caseros, às portas da cidade. Assim que assinou a carta de renúncia, o general Rosas se dirigiu até a legação britânica e solicitou asilo diplomático. O Encarregado de Negócios, Mr. Robert Gore, estava ciente que a vida de Rosas estava em perigo em função da efervescência política que tomava conta das ruas de Buenos Aires. Dessa forma, Mr. Robert Gore concordou com o asilo e na noite de 3 de fevereiro, acompanhado do secretário da legação, escoltou o general e a sua filha até o porto, onde tomaram uma pequena embarcação que os levou até a bordo da fragata inglesa Centaur.

Para justificar o pedido de ser levado à Inglaterra, o general Rosas argumentou "falta de recursos" ao almirante Henderson. Este concordou com a solicitação e o asilado foi transferido para bordo do navio de guerra inglês Conflict, que o levou até Plymouth. Assim que chegou ao território britânico, o navio foi saudado com uma salva de canhões. Esse ato fez com que o Ministro dos Negócios Estrangeiros fosse interpelado no Parlamento para justificar aquele ato. O Primeiro Ministro, duque de Northumberland, argumentou que os almirantes

\section{GANPHLAC}


britânicos tinham ordem de salvar as personalidades que estivessem na situação do exgovernador de Buenos Aires.

O general Juan Manuel Rosas agradeceu o asilo e solicitou à rainha Vitória permissão para residir na Inglaterra. Em resposta, a rainha disse que não precisava de autorização e que ele poderia residir onde bem entendesse e que estaria seguro sob a bandeira inglesa (GEGENA, 1960).

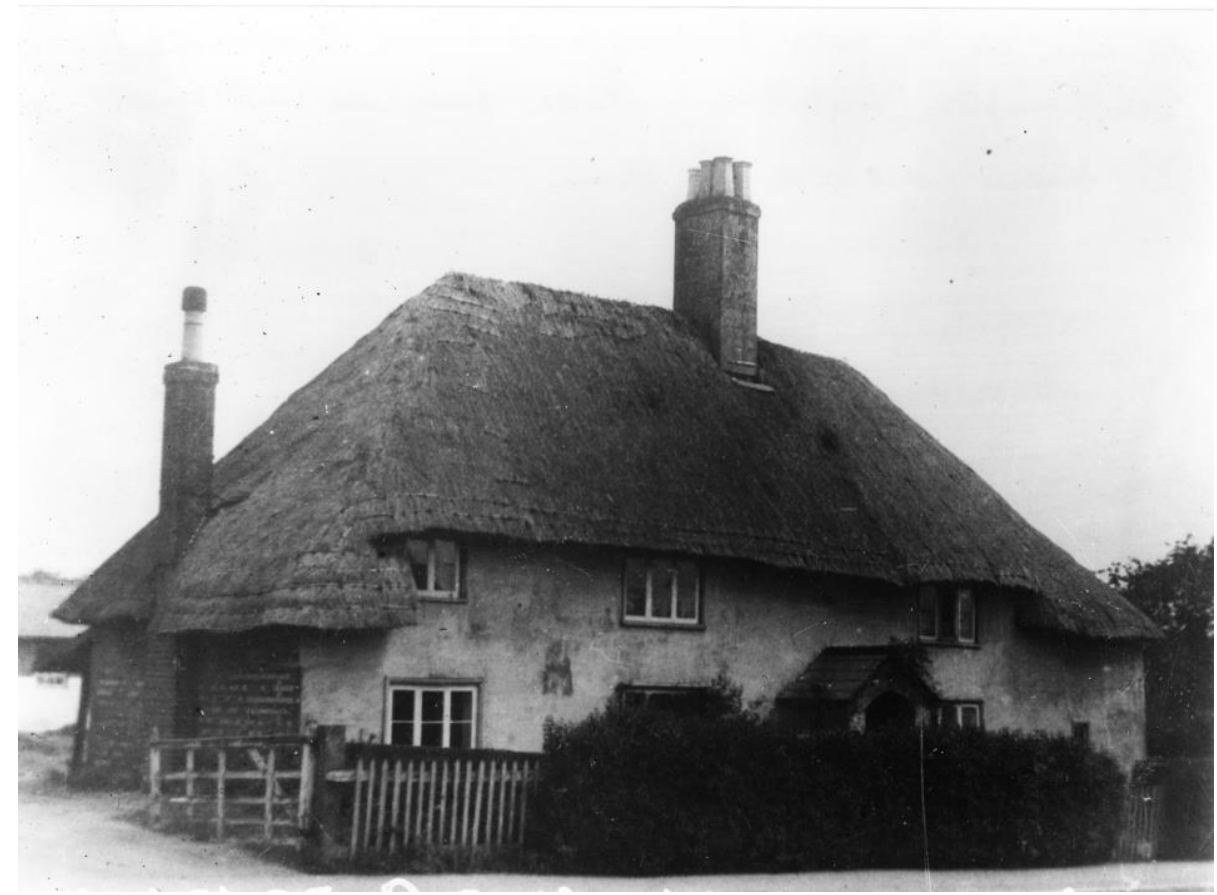

Casa em que Juan Manoel de Rosas viveu em Southampton.

Fonte: Archivo General de la Nación. Documento fotográfico. Inventario 226294.

Entre os episódios que tiveram uma entrega negociada dos asilados, destaca-se o caso do general haitiano Boisrond Canal, que solicitou asilo na casa de campo do Ministro estadunidense no Haiti, em 1875. No mês de maio daquele ano, o Haiti estava mergulhado em uma grande desordem política e social. O Presidente Domingue havia assinado um decreto que bania 44 pessoas acusadas de conspiração contra o governo. Alguns pelotões do Exército foram enviados para realizar as prisões e muitas pessoas eram mortas sumariamente nas ruas. Os exministros Pierre e Brice resistiram à prisão e foram encurralados em suas casas e mortos. Durante o fuzilamento, até mesmo os prédios dos consulados britânico e espanhol foram alvejados pelos tiros. Um dos pelotões foi enviado para casa de Boisrond Canal localizada perto da cidade de La Coup, já que ele era acusado de ser o líder da conspiração. Acompanhado de

\section{GANPHLAC}


mais quatro indivíduos, Canal foi para a casa de campo do Ministro dos Estados Unidos no Haiti, Mr. Bassett, porém, dois de seus companheiros foram mortos no caminho. Ao chegar à casa de campo de Mr. Bassett, lá já estavam outras três pessoas, Alerte, Iacinthe e Modé, todos incluídos no decreto de banimento. No dia 2 de maio, o Presidente Domingue assinou outro decreto colocando Boisrond Canal, e seus companheiros, "fora dos limites da lei" por terem pegado em armas para reagir a uma requisição legal. No dia seguinte, Mr. Bassett dirigiu-se até seu escritório em Port-au-Prince, onde recebeu uma nota do Secretário de Negócios Estrangeiros do Haiti, Mr. Excellent [sic]. A nota dizia que o governo havia sido informado que ele, Mr. Bassett, estava dando abrigo a certos revolucionários em sua casa, e o governo exigia uma lista com os nomes dessas pessoas. De forma similar, outra nota foi recebida exigindo a entrega de Modé, Iacinthe e Alerde. O Ministro dos Estados Unidos recusou-se a cumprir o estabelecido em ambas as notas por entender que esse procedimento de lista só era praticado no Haiti com a libertação ou embarque dessas pessoas para o exílio (MOORE, 1892, p. 216).

Ao retornar para sua casa, Mr. Bassett encontrou 1.500 soldados em desordem cercando sua residência, dificultando o seu trânsito e de sua família, impedindo o trânsito público pelas ruas, criando apreensões, cometendo violências pessoais e fazendo ameaças incendiárias (GILBERT, 1909, p. 567). Mr. Bassett solicitou que as tropas fossem retiradas daquela vizinhança e que fossem culpados os responsáveis por aqueles atos. O Ministro Mr. Excellent expressou seu pesar pelos atos desrespeitosos e garantiu que ordens haviam sido dadas para que os agentes do governo observassem as questões de respeito e cortesia em relação ao Ministro dos Estados Unidos, e que sua liberdade de ir e vir em total segurança fosse igualmente respeitada. Duas semanas depois, Alerte, Iacinthe, Modé e um dos companheiros de Boisrond Canal, foram permitidos a embarcar para o exílio, assim como outras duas pessoas que estavam na casa do Ministro britânico. Na casa de Mr. Bassett permaneceram apenas Boisrond-Canal e seu irmão mais novo (MOORE, 1892, p. 217).

Ao informar o seu governo sobre os incidentes ocorridos do mês de maio, $\mathrm{Mr}$. Bassett defendeu a concessão do asilo pela necessidade de prevenir que os refugiados fossem mortos. Também aproveitou a oportunidade para comentar que a concessão de asilo concedida pelo Ministro inglês foi muito bem recebida pelo Earl of Derby, Primeiro Ministro da Inglaterra. De qualquer modo, as notícias não agradaram Mr. Fish, Secretário de Estado dos Estados Unidos. Em sua resposta para Mr. Bassett, datada de 4 de junho, Mr. Fish dizia "lamentar que

\section{GANPHLAC}


você considera-se justificado por um impulso humanitário em conceder esse asilo" (MOORE, 1892, p. 218 $)^{11}$. Mr. Fish lembrava a seu subordinado que o asilo diplomático era uma prática sem fundamento no direito internacional e representava o contrário do que aquele governo acreditava. Em seguida, Mr. Fish acrescentava que se outros governos recebiam refugiados nessas ocasiões, isso não poderia ser considerado o suficiente para que o governo dos Estados Unidos sancionassem práticas similares adotadas pelos seus representantes. Além disso, o Departamento de Estado considerava que a prática do asilo era uma clara incitação contra os governos, já que as pessoas responsabilizadas por crimes de ofensa teriam a certeza de ser protegidas nas Legações Estrangeiras. No final do documento, Mr. Fish ainda relatava que o Ministro do Haiti acreditado nos Estados Unidos, Mr. Preston, havia conferenciado consigo sobre aquela situação. Naquela oportunidade, Mr. Fish teria dito que era preferível que o asilo não tivesse ocorrido, mas que deixaria ordens claras para que o seu Ministro (Mr. Bassett) não recusasse solicitações de entrega dos asilados para serem julgados, desde que os asilados não fossem punidos e recebessem autorização de deixar o país sem serem molestados (MOORE, 1892, p. 218) $)^{12}$.

Após alguma controvérsia, um acordo foi firmado entre o Secretário de Estado, Mr. Fish, e o Ministro do Haiti nos Estados Unidos, Mr. Preston, em 27 de setembro de 1875. O acordo previa a anistia de todas as ofensas a partir do momento em que os asilados partissem da ilha. Assim, Mr. Bassett entregaria os asilados que seriam escoltados por uma força militar

\footnotetext{
${ }^{11}$ Tradução livre do inglês: "It is regretted that you deemed yourself justified by an impulse of humanity to grant such an asylum".

12 Antes de Mr. Bassett receber essas instruções, porém, ocorreram novos acontecimentos. Aquele grupo de militares ao redor da casa do Ministro dos Estados Unidos voltou a se comportar de forma insolente. As tropas começaram a passar a noite inteira gritando e fazendo barulhos, o que tornava impossível para qualquer pessoa dormir dentro da casa. No dia 26 de junho, Mr. Bassett enviou uma nota para o Ministro dos Negócios Estrangeiros do Haiti, Mr. Excellent, dizendo não questionar o direito das tropas em realizar operações dentro dos territórios de jurisdição haitiana, mas considerava que esses direitos não poderiam transgredir os direitos e imunidades dos ministros estrangeiros. A reclamação realizada pelo Mr. Bassett chegou até o conhecimento do Departamento de Estado em Washington. Mr. Cadwalader, que atuava interinamente como Secretário de Estado, enviou uma nota, em 6 de agosto, para o Ministro haitiano Mr. Preston. A nota dizia não acreditar que aquelas incomodações (os gritos na madrugada) haviam sido instigadas pelo governo haitiano, e que talvez esse governo nem soubesse o que estava ocorrendo. Entretanto, o governo dos Estados Unidos acreditava que aquela prática cessaria imediatamente. Caso contrário, aquele ato seria visto como um procedimento de inimizade partindo do governo haitiano, e que seria da opinião do Presidente dos Estados Unidos que um navio de guerra devesse visitar Port-au-Prince (MOORE, 1892, p. 219). No dia 7 de setembro de 1875, o Secretário de Estado interino, Mr. Hunter, informou a Mr. Bassett que havia sido determinado que um navio de guerra dos Estados Unidos fosse enviado para Port-auPrince para "proteção do insulto" sofrido. Essa decisão foi tomada depois que um documento enviado por $\mathrm{Mr}$. Bassett, datado do dia 2 setembro, chegou ao conhecimento do Departamento de Estado. Neste documento, Mr. Bassett comunicava que as incomodações noturnas haviam aumentado, e que o governo haitiano resolveu julgar os refugiados à revelia, e que vários haviam sido condenados à morte.
}

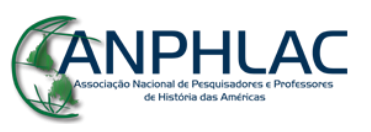

Revista Eletrônica da ANPHLAC, ISSN 1679-1061, №. 19, p. 06-24, jul./dez., 2015.

http://revista.anphlac.org.br 
haitiana, sob a supervisão do próprio Mr. Bassett, até um navio de outra nacionalidade rumo ao exílio. Os asilados também estariam impossibilitados de retornar ao Haiti sem a permissão do governo haitiano. Em consequência, no dia 2 de outubro o Presidente Domingue publicou outro decreto que comutou as sentenças de morte dos asilados para o banimento por toda a vida do território do Haiti. No dia 5 de outubro, os asilados acompanhados por tropas haitianas, pelo Mr. Bassett e pelo Encarregado de Negócios da França, embarcaram em navios rumo ao exílio (MOORE, 1892, p. 220).

Algumas semanas depois do embarque, Mr. Preston enviou uma série de proposições ao governo dos Estados Unidos que buscavam regulamentar a prática do asilo no Haiti. Entre essas proposições, destacam-se: que os asilos nunca deveriam ser concedidos a criminosos comuns; que somente deveria ser acordado asilo para criminosos políticos e em casos excepcionais; que quando o governo haitiano exigisse a entrega desses refugiados eles deveriam ser entregues para a justiça; e que uma vez entregue para a justiça, o Ministro residente poderia usar sua influência para garantir a segurança dos asilados e a comutação da pena. A resposta de Mr. Fish foi de que, embora algumas daquelas proposições fossem "bastante justas", os Estados Unidos não iriam adotá-las sozinhos, sem a concordância e aceitação das demais potências, e que era preferível analisar a aplicação do asilo em cada caso (MOORE, 1892, p. 221).

Por fim, um caso ilustrativo dos conflitos que terminaram com a violação do asilo aconteceu no México. Em janeiro de 1877, durante a "revolução" que levou à presidência o General Porfirio Díaz, o seu adversário, o General Arce solicitou refúgio no consulado dos Estados Unidos. Alguns dias depois, o Cônsul informou ao comandante das forças de Díaz, o Coronel Ramirez, que o General Arce estava sob a proteção do Consulado. O Coronel Ramirez garantiu que o Consulado seria respeitado. Em 20 de fevereiro, o Ministro dos Estados Unidos na Cidade do México, Mr. J. W. Foster, ao saber do refúgio do General Arce no Consulado dos Estados Unidos escreveu que os consulados não possuíam o direito de extraterritorialidade, e que enquanto é um ato de humanidade proteger os indefesos da violência das massas e das vinganças durante as mudanças governamentais, é aconselhável evitar a concessão de proteção permanente para refugiados políticos para prevenir conflitos com as autoridades locais ${ }^{13}$. 13 Apenas na década de 1960 que os consulados foram considerados espaços beneficiados pela
extraterritorialidade.

\section{CANPHLAC}

Revista Eletrônica da ANPHLAC, ISSN 1679-1061, №. 19, p. 06-24, jul./dez., 2015.

http://revista.anphlac.org.br 
Entretanto, antes que essas instruções chegassem até o consulado, um grupo de militares armados invadiu o consulado na ausência do Cônsul e tiraram à força o General Arce. Ao saber do ocorrido, o Coronel Ramirez prometeu que traria de volta o General Arce e puniria os responsáveis pelo ato. Porém, nem o pedido de desculpas veio, nem o próprio General foi devolvido. O Ministro dos Estados Unidos, Mr. Foster, ainda enviou uma nota reportando os fatos para o Ministro das Relações Exteriores do México, mas apenas recebeu a promessa de que os culpados seriam punidos por terem faltado com a cortesia para com a bandeira dos Estados Unidos. O caso não passou disso e o General Arce permaneceu como prisioneiro do General Porfirio Díaz (MOORE, 1892).

A falta de normativas internacionais que regulassem esses episódios fez com que diversos países procurassem estabelecer regras gerais de conduta para as questões de asilo político. Foi nesse espírito que aconteceu em Montevidéu, em 1889, o primeiro Congresso Sulamericano de Direito Internacional que reconheceu, no artigo 16, que "El Asilo es inviolable para los perseguidos por delitos políticos", porém, o mesmo artigo reconhecia a necessidade de limitação desse direito, "pero la Nación de refugio tiene el deber de impedir que los asilados realicen en su territorio actos que pongan en peligro la paz pública de la Nación contra la cual han delinquido" (QUINTANA, 1952, p. 53-54). O tratado foi subscrito por Argentina, Bolívia, Brasil, Chile, Paraguai, Peru e Uruguai, sendo que apenas o Brasil e o Chile não ratificaram o $\operatorname{tratado}^{14}$.

\section{Considerações Finais}

Como se viu, ao longo do século XIX a América Latina foi o palco de diversos casos de asilos diplomáticos que aconteceram em embaixadas, consulados, navios de guerra e outros espaços. Para o século XIX, as práticas de asilo e refúgio são vistas como sinônimos, não havendo diferenciações entre esses conceitos. Entretanto, ao longo do século XX nasceu uma nova categoria jurídica internacional em função dos grandes deslocamentos humanos provocados pelas guerras mundiais. Desde então, há uma grande confusão terminológica em relação aos conceitos de asilo e refúgio (ver, por exemplo: FERNÁNDEZ, 2003; SAN JUAN;

\footnotetext{
${ }^{14}$ São necessárias pesquisas específicas sobre a participação de todos esses países no congresso para compreender melhor os pormenores da ratificação ou não do tratado por cada Estado.
}

\section{GANPHLAC}


MANLY, 2003). Não há dúvidas, porém, sobre a necessidade de compreender essas diferenciações conceituais para conseguir se posicionar de maneira acertada em questões tão contemporâneas como as migrações forçadas de africanos para a Europa, ou até mesmo de haitianos para o Brasil.

Nesse sentido, estudar as políticas de concessão de asilo na América Latina no século XIX nos ajuda a perceber de que forma essa prática colaborou efetivamente para o desenvolvimento dos direitos humanos na região. Os exemplos descritos na terceira parte deste artigo demonstram que tanto no caso em que o asilo foi mantido (Rosas) ou no episódio em que os refugiados foram entregues após negociação (Boisrond Canal), as atuações diplomáticas foram importantes para que houvesse um mínimo de respeito à condição humana. No caso em que o asilo foi violado (General Arce), ao contrário, vimos prevalecer a força sobre a cordialidade.

Se retomarmos a afirmação de Niklaus Steiner, no seu livro Arguing about Asylum, ao dizer que "o outorgamento de asilo a um refugiado é uma crítica implícita ao tratamento de outro país a seus cidadãos, pelo qual os Estados são geralmente rápidos em aceitar refugiados de seus inimigos, mas duvidosos de aceitar os de amigos" (STEINER, 2003, p. 3-4 apud SNAJDER, 2011, p. 69) ${ }^{15}$, teremos que pensar as concessões de asilo para além da dimensão contingencial. Em nossa pesquisa, o elevado número de casos de asilos diplomáticos mapeados nos levou a ponderar que essa prática pode ter colaborado para a instabilidade política da América Latina.

Para validar essa hipótese, acreditamos ser necessário mais estudos sistemáticos sobre cada um desses episódios, realizando-se pesquisas sobretudo em arquivos diplomáticos. Pois, como bem disse Pablo Yankelevich, "remexer com maior cuidado nestes acervos permitiria mensurar melhor a distância entre comportamentos governamentais e ações individuais dos agentes diplomáticos" (2011, p. 18).

\footnotetext{
${ }^{15}$ Mesmo que o autor reflita sobre outro contexto histórico, consideramos que sua assertiva pode ser aplicada ao século XIX. A citação completa é: "O outorgamento de asilo a um refugiado é uma crítica implícita ao tratamento de outro país a seus cidadãos, pelo qual os Estados são geralmente rápidos em aceitar refugiados de seus inimigos, mas duvidosos de aceitar os de amigos. Uma política de asilo assim foi comum durante a Guerra Fria [...] Os Estados Unidos na década de 1980 geralmente admitiram a entrada de pessoas da Nicarágua e cubanos, mas rechaçaram exilados e refugiados de El Savador e Haiti". (Steiner, 2003, p. 3-4 apud Snajder, 2011, p. 69).
}

\section{CANPHLAC}

Revista Eletrônica da ANPHLAC, ISSN 1679-1061, №. 19, p. 06-24, jul./dez., 2015.

http://revista.anphlac.org.br 


\section{Referências bibliográficas}

BELLO, Andrés. Principios de derecho internacional. 4 ed., Santiago de Chile: Librería Central de Mariano Servat, 1886.

BURGESS, Greg. Refuge in the land of liberty: France and its Refugees, from the Revolution to the End of Asylum (1787-1939). Great Britain - Eastbourne: Palgrave Macmillan, 2008.

ELIAS, Norbert. O Processo Civilizacional. Lisboa: Publicações Dom Quixote, 1990. 2v.

ESPIELL, Héctor Gros. Andres Bello y su proyeccion en el Derecho Internacional. Cuadernos del Instituto Matias Romero de Estudios Diplomaticos. N. 6., México: Secretaria de Relaciones Exteriores, 1982.

ESTÉVEZ, José B. Acosta. La internacionalización de los derechos humanos y los mecanismos de protección de los refugiados. In: MIRABET, Núria Camps (ed.). El derecho internacional ante las migraciones forzadas: refugiados, desplezados y otros migrantes involuntarios. Lleida: Edicions de la Universitat de Lleida, 2005.

FERNÁNDEZ, Jaime Esponda. La tradición latinoamericana de asilo y la protección internacional de los refugiados. IN: FRANCO, Leonardo (coord.). El asilo y la protección internacional de los refugiados en América Latina. Buenos Aires: Siglo XXI Editores Argentina, 2003. p. 75-121.

FREITAS, Carlos Vidal de Oliveira. Elementos de Direito Internacional Maritimo. Rio de Janeiro: Lombaerts \& Comp, 1884.

GIGENA, Carlos Torres. Asilo Diplomático: su práctica y su teoría. Buenos Aires: La Ley S. A. Editora e Impresora, 1960.

GILBERT, Barry. The Practice of Asylum in Legations and Consulates of United States. In: The American Journal of International Law, Vol. 3, No. 3, (jul., 1909), p. 562-595.

HUNT, Lynn. A invenção dos direitos humanos: uma história. São Paulo: Companhia das Letras, 2009.

MAGALHÃES, José Calvet de. Manual Diplomático: Direito Diplomático, Prática Diplomática. 5 ed., Lisboa: Editorial Bizâncio, 2005.

MOORE, John Bassett. Asylum in Legations and Consulates and in Vessels III. Political Science Quarterly. Vol. VII., N 3, Setembro de 1892, p. 397-418.

QUINTANA, Lucio M. Moreno. Derecho de Asilo. Buenos Aires: Imprensa de la Universidad, 1952.

\section{CANPHLAC}

Revista Eletrônica da ANPHLAC, ISSN 1679-1061, №. 19, p. 06-24, jul./dez., 2015.

http://revista.anphlac.org.br 
RACINE, Karen. Nature and Mother: Foreign Residence and the Evolution of Andrés Bello's American Identity, London, 1810-1829. In: FEY, Ingrid E.; RACINE, Karen (ed.). Strange Pilgrimages: Exile, Travel, and National Identity in Latin America, 1800-1990s. Wilmington, Delaware: SR Books, 2000, p. 3-19.

RONIGER, Luis; SZNAJDER, Mario. The politics of exile in Latin America. Cambridge: Cambridge University Press, 2009.

SAN JUAN, César Walter; MANLY, Mark. El asilo y la protección internacional de los refugiados en América Latina: análisis crítico del dualismo "asilo-refugio" a la luz de Derecho Internacional de los Derechos Humanos. In: FRANCO, Leonardo (coord.). El asilo y la protección internacional de los refugiados en América Latina. Buenos Aires: Siglo XXI Editores Argentina, 2003, p. 18-71.

SEIJAS, Rafael F. El Derecho Internacional Hispano-Americano (público e privado). Caracas: Imprenta de "El Monitor", 1884. Tomo Segundo.

SNAJDER, Mario. Os exílios latino-americanos. In: QUADRAT, Samantha Viz (org.). Caminhos Cruzados: história e memória dos exílios latino-americanos no século XX. Rio de Janeiro: Editora FGV, 2011, p. 65-90.

VAN SCHAIK, Angelo; KRINNINGER, Theresa. Tragédias no Mediterrâneo mudam rotina de Lampedusa. Matéria publicada no Deutsche Welle. Disponível em: http://www.dw.com/pt/tragédias-no-mediterrâneo-mudam-rotina-de-lampedusa/a-18388573. Acesso em: 22 de agosto de 2015.

VIADEMONTE, José Agustín Martínez. El Derecho de Asilo y el Régimen Internacional de Refugiados. México, D.F.: Ediciones Botas, 1961.

YANKELEVICH, Pablo. Estudar o exílio. In: QUADRAT, Samantha Viz (org.). Caminhos Cruzados: história e memória dos exílios latino-americanos no século XX. Rio de Janeiro: Editora FGV, 2011, p. 11-30.

ZARATE, Luis Carlos. El asilo en el Derecho Internacional Americano. Bogota, D. E. Colombia: Editorial Iqueima, 1958. 